\title{
Development of a Disease Risk Prediction Model for Downy Mildew (Peronospora sparsa) in Boysenberry
}

\author{
Kwang Soo Kim, Robert M. Beresford, and Monika Walter
}

First author: Department of Plant Science, Seoul National University, Seoul, 151-921, Korea, and Research Institute for Agriculture and Life Sciences, Seoul National University, Seoul, 151-921, Korea; second author: Pathology and Applied Mycology, Mount Albert Research Centre, The New Zealand Institute for Plant \& Food Research Ltd., Private bag 92 169, Mt. Albert, New Zealand; and third author: Pathology and Applied Mycology, The New Zealand Institute for Plant \& Food Research Limited, 55 Old Mill Road, RD3, Motueka, New Zealand.

Accepted for publication 9 July 2013.

\section{ABSTRACT}

Kim, K. S., Beresford, R. M., and Walter, M. 2014. Development of a disease risk prediction model for downy mildew (Peronospora sparsa) in boysenberry. Phytopathology 104:50-56.

Downy mildew caused by Peronospora sparsa has resulted in serious production losses in boysenberry (Rubus hybrid), blackberry (Rubus fruticosus), and rose (Rosa sp.) in New Zealand, Mexico, and the United States and the United Kingdom, respectively. Development of a model to predict downy mildew risk would facilitate development and implementation of a disease warning system for efficient fungicide spray application in the crops affected by this disease. Because detailed disease observation data were not available, a two-step approach was applied to develop an empirical risk prediction model for $P$. sparsa. To identify the weather patterns associated with a high incidence of downy mildew berry infections (dryberry disease) and derive parameters for the empirical model, classifi- cation and regression tree (CART) analysis was performed. Then, fuzzy sets were applied to develop a simple model to predict the disease risk based on the parameters derived from the CART analysis. High-risk seasons with a boysenberry downy mildew incidence $>10 \%$ coincided with months when the number of hours per day with temperature of 15 to $20^{\circ} \mathrm{C}$ averaged $>9.8$ over the month and the number of days with rainfall in the month was $>38.7 \%$. The Fuzzy Peronospora Sparsa (FPS) model, developed using fuzzy sets, defined relationships among high-risk events, temperature, and rainfall conditions. In a validation study, the FPS model provided correct identification of both seasons with high downy mildew risk for boysenberry, blackberry, and rose and low risk in seasons when no disease was observed. As a result, the FPS model had a significant degree of agreement between predicted and observed risks of downy mildew for those crops $(P=0.002)$.
Downy mildew (caused by Peronospora sparsa Berk.), a disease of boysenberry (Rubus hybrid), has caused severe fruit loss in New Zealand (20). Boysenberry plants, which bear fruit on 2-year-old canes, are highly susceptible to $P$. sparsa (5), with fruit becoming dry and shriveled after infection; hence, the disease is also known as dryberry. $P$. sparsa also causes downy mildew of rose, which has been a sporadic but continuing problem for growers in the United States and the United Kingdom $(2,21)$. The pathogen infects foliage, flowers, and berries of boysenberry in spring after overwintering as mycelium in roots, crowns, buds, and canes $(17,20)$. Unfolding leaves show symptoms following apical shoot growth of the primocane, which is the emergent, nonfruiting cane in its first year. Infected leaves produce sporangia that germinate and infect sepals, pedicels, and developing fruit which occur on floricanes (second-year fruiting canes) (17). Sporangial production occurs on the lower surface of leaves in the lower part of the canopy where wetness and humidity generally are highest. This makes it difficult to detect the disease at an early stage. Tate (17) suggested that $P$. sparsa could cause systemic infections under wet conditions. Oospores that develop on leaves, sepals, and roots can be transported to new areas by wind and water (10).

Fungicidal sprays and cultural management have been used to control downy mildew in boysenberry. For example, removal of

Corresponding author: K. S. Kim; E-mail address: luxkwang@ @ snu.ac.kr

http://dx.doi.org/10.1094/PHYTO-02-13-0058-R

(c) 2014 The American Phytopathological Society leaf litter, rooted ends of primocanes, and rootsuckers is recommended in order to reduce early inoculum production $(20,21)$. Along with this cultural management, fungicide applications are needed to deter development of the disease during wet seasons $(9,14,18,20)$.

A disease warning system that quantifies the risk of downy mildew in relation to weather conditions would support growers' decisions about application of fungicides (8). Environmental conditions are important in the infection processes of downy mildew (3). Aegerter et al. (3) reported that the critical condition for the development of downy mildew in rose was a leaf wetness duration of $8.4 \mathrm{~h}$ /day over 10 days. Although wetness duration has been identified as a critical variable for downy mildew development, leaf wetness parameters are rarely measured by standard weather stations. Construction of a downy mildew forecasting model that uses weather data from standard weather stations would provide greater flexibility for implementation of a disease warning system in areas where wetness data are not available.

No model has been developed to quantify the effects of weather conditions on the risk of disease caused by $P$. sparsa without leaf wetness duration. The objectives of this study were to investigate the relationship between monthly weather conditions and the risk of boysenberry downy mildew, and to develop a disease risk model which would facilitate effective fungicide management. Because the disease occurs sporadically and few detailed disease observations are available in the literature (3), it would be challenging to develop a mechanistic model, which would require detailed disease observation (e.g., spore counts as well as weather data). However, disease records at the end of seasons were available from our own surveys and published records and this allowed 
an empirical disease risk model for $P$. sparsa to be developed in this study. The disease risk model was initially developed and validated at the inter-seasonal and inter-regional scales using data on $P$. sparsa development in New Zealand (boysenberry) and published data from the United States (rose) and Mexico (blackberry) $(3,15)$. Then, applicability of the model for daily risk assessment was examined using published disease data from the United States (3).

\section{MATERIALS AND METHODS}

Study areas. Incidence of downy mildew was recorded on commercial boysenberry orchards near Nelson and Hawke's Bay, which are the major production areas in New Zealand (Table 1). Disease incidence assessment in Nelson was performed at five to seven commercial sites, except for the 2011-12 season, when only three sites were available. Nelson grower properties were located within a $25-\mathrm{km}$ radius of the wider Nelson area, stretching from Richmond to the Lower Moutere Valley. The Hawke's Bay site was near Havelock North. At each grower site, designated plot areas were identified and maintained by the growers, except that they received no downy mildew fungicide sprays. Disease monitoring of infected primocanes, leaves, and fruit was conducted regularly (e.g., weekly or fortnightly) on sprayed and unsprayed rows (20). The disease incidence was assessed in gardens in Nelson from 2000 to 2011 and in Hawke's Bay in 2001. Disease incidence, as percentage of fruit diseased, was averaged among growers for each region. Disease observations of rose downy mildew in Wasco, CA in the United States between 1998 and 1999 were obtained from a previous report (3). Blackberry downy mildew was reported in Tangancicuaro and Atapan, Michoacan, Mexico for 2007 and 2008 seasons (15).

The records of disease incidence were pooled into two groups, one of which was used for calibration and the other for validation (Table 1). Disease records collected in the Nelson area were used for calibration because they were available for 10 years (20002009). Validation records comprised the remaining 5 years of disease records. These included 2 years (2010-2011) from Nelson, which allowed accuracy of the model calibrated at Nelson sites to be tested, and 1 year (2001) from Hawke's Bay, which tested the model outside of the calibration region. Disease records for 2 years (1998-1999) from Wasco, which indicated degree of disease incidence (e.g., high or low), and disease records from the Mexican sites were included in the validation sets.

Weather data. Daily weather data were obtained from the National Climate Data Center Global Surface Summary of the Day (GSOD) database, which has been used for ecological studies on insects and pathogens $(4,11,12)$. In New Zealand, weather stations near Nelson and Hawke's Bay, which is Nelson Aero AW (935460/99999) and Napier Aerodrome AW (933730/99999), respectively, provided the GSOD data for 20002011 and 2001-2002, respectively. In the previous study on rose, Aegerter et al. (3) used the California Irrigation Management Information System (CIMIS) network to obtain weather data near the San Joaquin Valley. In the present study, however, weather data were collected from the GSOD station at Bakersfield (Bakersfield/Meadows, $723840 / 23155$ ), which is $\approx 30 \mathrm{~km}$ distant from the CIMIS station, because the GSOD database provides open access to the public.

The GSOD data set contains daily precipitation and rain- and snow-day indicators. It was assumed that rainfall has occurred on days with precipitation $>0.254 \mathrm{~mm}$ and no snowfall. On days when precipitation was 0 or missing but the rain-day indicator showed occurrence of rainfall, it was also assumed that rainfall occurred on the day. These rainfall day data were summarized to calculate the frequency of days with rain as a percentage in a given month.

Because no weather data were available for disease risk prediction at Mexican sites during the 2007 and 2008 seasons even from GSOD weather stations, the Prediction of Worldwide Energy Resource (POWER) data set managed by the National Aeronautics and Space Administration (NASA) were used to obtain daily weather data (http://power.larc.nasa.gov). Because of low spatial resolution of the data set, weather data for both Mexican sites were identical. Elevation of two Mexican sites in the POWER data was considerably lower than actual elevation. For example, the elevations of Tangancicuaro and Atapan are $\approx 1,700$ and $1,600 \mathrm{~m}$, respectively, whereas the POWER sets indicated that those of two cities are $1,300 \mathrm{~m}$. Thus, the lapse rate of $6.5^{\circ} \mathrm{C} \mathrm{km}^{-1}$ were applied to adjust temperatures from the POWER data sets.

Variables for a disease risk model. Variables to predict the risk of boysenberry downy mildew were inferred from previous studies on rose downy mildew. Aegerter et al. (3) reported that the optimum temperatures for downy mildew infection and colonization of rose leaves were 15 to 20 and 20 to $25^{\circ} \mathrm{C}$, respectively.

TABLE 1. Incidence of boysenberry and rose downy mildew at harvest assessed in New Zealand (Nelson and Hawke's Bay), the United States (Wasco, CA), and Mexico (Tangancicuaro and Atapan), respectively

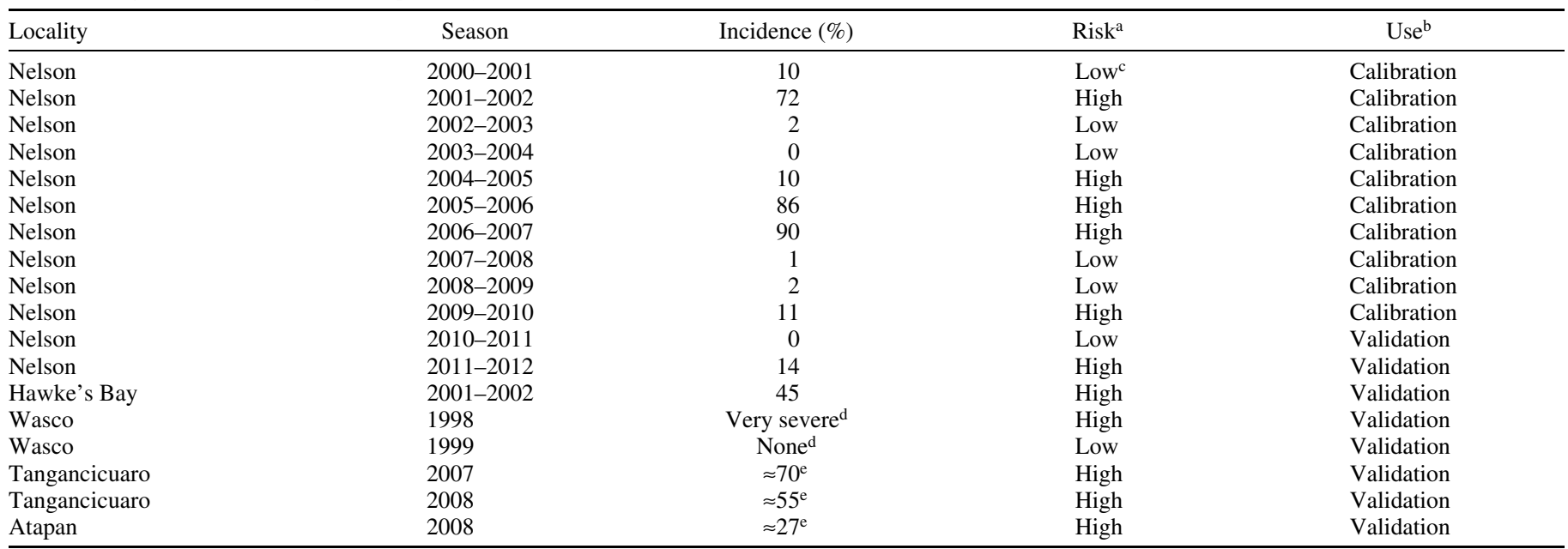

a Incidence of fruit infection $>10 \%$ represents the high risk of boysenberry downy mildew in a season.

${ }^{\mathrm{b}}$ Use of disease observation for model development.

c Actual incidence was $9.7 \%$.

${ }^{\mathrm{d}}$ No quantity of incidence is available in Aegerter et al. (3), from which data were obtained.

e Incidence of fruit infection was estimated from figures in Rebollar-Alviter et al. (15). 
Thus, the hours when the temperature was between 15 and $20^{\circ} \mathrm{C}$ and between 20 and $25^{\circ} \mathrm{C}$ were used as further input variables to represent temperature conditions for development of boysenberry downy mildew. Because downy mildew occurs readily when wetness duration $>8 \mathrm{~h}$ /day occurs over 10 days (3), a wetness period was selected as an input variable to the model. For monthly risk prediction using daily weather data, the average number of hours in these temperature ranges for 24-h periods and the frequency of days with rain (percent) in a month were used to represent temperature and wetness conditions, respectively. It was assumed that disease risk would increase with increasingly optimal temperature conditions (7) and rainfall frequency (19).

Daily temperature data were summarized as an average number of hours per day in a specified temperature range (e.g., 15 to $20^{\circ} \mathrm{C}$ ). The WAVE method was used to estimate the hourly temperature $T_{t}$ for a given time $t$ from the daily maximum $T_{X}$ and minimum $T_{N}$ temperatures $(4,16)$ :

$T_{t}=\left\{\begin{array}{cc}T_{A}-\frac{T_{R}}{2} * \cos \left[\pi \cdot\left(t-t_{R}\right) /\left(t_{X}-t_{E}\right)\right] & \left(t_{R}<t \leq t_{X}\right) \\ T_{A N}+\frac{T_{R}}{2} * \cos \left[\pi \cdot\left(t-t_{X}\right) /\left(10+t_{R}\right)\right] & \left(t \leq t_{R} \text { or } t>t_{X}\right)\end{array}\right.$

where $t_{R}$ and $t_{X}$ represent the time of sunrise and the hour at which the maximum temperature occurred in a day, respectively. The value of $t_{R}$ and $t_{X}$ varied by month $(4,12) . T_{A}$ and $T_{R}$ were the average and range of temperature in a day, respectively, and were calculated as follows:

$$
T_{A}=\left(T_{X}+T_{N}\right) / 2
$$

and

$$
T_{R}=\left(T_{X}-T_{N}\right)
$$

$T_{A N}$ and $T_{R N}$, which were the average and diurnal range of temperature for a $24-\mathrm{h}$ period from $t_{X}$, respectively, were calculated using equations 2 and 3 , respectively, with $T_{N}$ in the next day. $T_{t}$ values were estimated from $t_{R}$ every minute.

Temperature and rainfall thresholds for $\boldsymbol{P}$. sparsa risk. Because only seasonal disease records were available, a data mining approach was used to detect those specific weather conditions occurring in seasons when the risk of $P$. sparsa was high. The seasonal disease risk was determined using the surveyed incidence of boysenberry downy mildew at harvest at commercial grower sites. It was assumed that incidence of fruit infection $>10 \%$ represents a high risk of boysenberry downy mildew in a season. Ten percent fruit loss due to downy mildew fruit infection (i.e., visible dryberry symptoms) has been considered by the New Zealand boysenberry industry as the threshold above which significant economic loss occurs (G. Langford, personal communication). This economic loss is due to reductions in yield and increased labor costs for grading and removing the berries with the dryberry symptoms.

It was assumed that there would be at least 1 month during which temperature and rainfall variables would exceed a set of thresholds in a season with high risk of $P$. sparsa. To identify the thresholds that represent specific conditions favorable for the development of downy mildew, the classification and regression tree (CART) analysis was performed. The CART analysis has been used as a data mining tool (6). Each month, subject to the CART analysis, was assigned the degree of risk for a given season that corresponded to the degree of risk used as the response variable for that season. For example, the incidence was $72 \%$ at harvest in the 2000-01 season. Thus, October, November, and December 2001 were labeled high risk. This made it possible for the CART analysis to compare and differentiate monthly weather conditions associated with the risk of P. sparsa between high and low risk seasons.
The hours in set temperature ranges $\left(15\right.$ to $20^{\circ} \mathrm{C}$ and 20 to $25^{\circ} \mathrm{C}$ ) and rainfall frequency in the month were used as predictor variables. Aegerter et al. (3) reported that optimal temperatures for infection and colonization of rose downy mildew were 15 to $20^{\circ} \mathrm{C}$ and 20 to $25^{\circ} \mathrm{C}$, respectively. Therefore, these two sets of temperature ranges, were examined as possible predictor variables.

In the CART analysis, data are classified into one of two groups according to a threshold for one of the predictor variables (e.g., either temperature or rainfall). Each group is subjected to a test to examine whether it can be partitioned further using another threshold for other predictor variables and, thus, a tree of partition is formed. The decision tree obtained from the CART analysis was restructured to identify weather conditions associated with high risk of boysenberry downy mildew. JMP (version 9.0; SAS Institute Inc., Cary, NC) was used to perform the CART analysis.

Fuzzy sets of weather conditions for development of boysenberry downy mildew. $P$. sparsa outbreaks occur sporadically (3), which makes it challenging to collect a relatively large number of disease observations for developing a mechanistic simulation model, machine-learning algorithm, or multivariate statistical model for disease risk prediction. A model based on fuzzy sets can be developed without an extensive set of observations because fuzzy sets can be defined using the opinions of experts (13). Fuzzy sets were defined to quantify weather conditions in relation to outbreaks of boysenberry downy mildew, using disease observations for 10 site-years and existing knowledge on the effect of weather conditions on development of boysenberry downy mildew.

A fuzzy set has members that have degrees of membership between 0 and 1, rather than a binomial membership (e.g., yes or no). When $x$ is a member of a fuzzy set $X$, the degree to which $x$ is actually a member of $X$ is defined using a membership function. The membership function assigns a value between 0 and 1 to each element of the fuzzy set. For example, $x$ can be a member of $X$ at the degree of 0.3 .

A pair of membership functions relating to temperature $\left(\mu_{T}\right)$ and rainfall frequency, $\left(\mu_{P}\right)$, were defined for the fuzzy sets associated with the average number of hours in a specified temperature range for 24-h periods, $T_{m}$, and the frequency of days with rain (percent), $P_{m}$, in a month, $m$, respectively (Fig. 1). Membership functions of $\mu_{T}$ and $\mu_{P}$ were defined as follows:

$$
\begin{aligned}
& \mu_{T}\left(T_{m}\right)=\left\{1+\exp \left[-\mathrm{S}_{T} \cdot\left(T_{m}-K_{T}\right)\right]\right\} \\
& \mu_{P}\left(P_{m}\right)=\left\{1+\exp \left[-\mathrm{S}_{P} \cdot\left(P_{m}-K_{P}\right)\right]\right\}
\end{aligned}
$$

The sigmoid curve was chosen to define $\mu_{T}$ and $\mu_{P}$ because the curve can represent increasing risk of disease with increasing hours in the temperature range and rainfall frequency. In addition, it requires only a pair of parameters, $K$. and $S$., which represent a threshold of favorable conditions and a measure of risk increase for downy mildew development, respectively.

Formulation of a risk model. The monthly values of $\mu_{T}$ and $\mu_{P}$ were combined to determine the degree of monthly risk, $\Phi_{m}$, as follows:

$$
\Phi_{m}=\mu_{T}\left(T_{m}\right) \cdot \mu_{P}\left(P_{m}\right)
$$

Equation 6 indicates the degree to which temperature was ideal for infection and rainfall was frequent in relation to development of boysenberry downy mildew in $m$. A risk index, $R_{m}$, in a given month was calculated as follows:

$$
R_{m}=\max \left(\frac{\Phi_{m}-\Phi_{r}}{\Phi_{m}+\Phi_{r}}, 0\right)
$$

where $r$ is a reference month that represents an early stage in the season when plants are yet to grow and, as a result, no symptoms 
develop. In New Zealand, $r$ was assumed to be September, because symptoms begin to appear in October (17). In the United States, the value of $r$ was assumed to be December, because growth of plants starts in January or February and infection would start to occur in these months in California (1). In Mexico, the $r$ value was assumed to be May because bud break occurs during June and July (15). The seasonal risk of downy mildew at harvest $R_{H}$ was calculated as follows:

$$
R_{H}=\max \left(R_{r+1}, R_{r+2}, R_{r+3}\right)
$$

Then, the value of $R_{H}$ was used to predict the risk of boysenberry downy mildew. It was assumed that high risk of boysenberry downy mildew occurred when the value of $R_{H}$ was $>0.5$. For risk prediction of blackberry downy mildew, weather conditions from June to November were considered because the growing period from the reference month was longer than other crops. The model based on fuzzy sets was designated the Fuzzy Peronospora Sparsa (FPS) model.

Determination of parameters. Iterative processes were used to find the optimum values of parameters. Thresholds of temperature and rainfall variables, which were identified from the CART
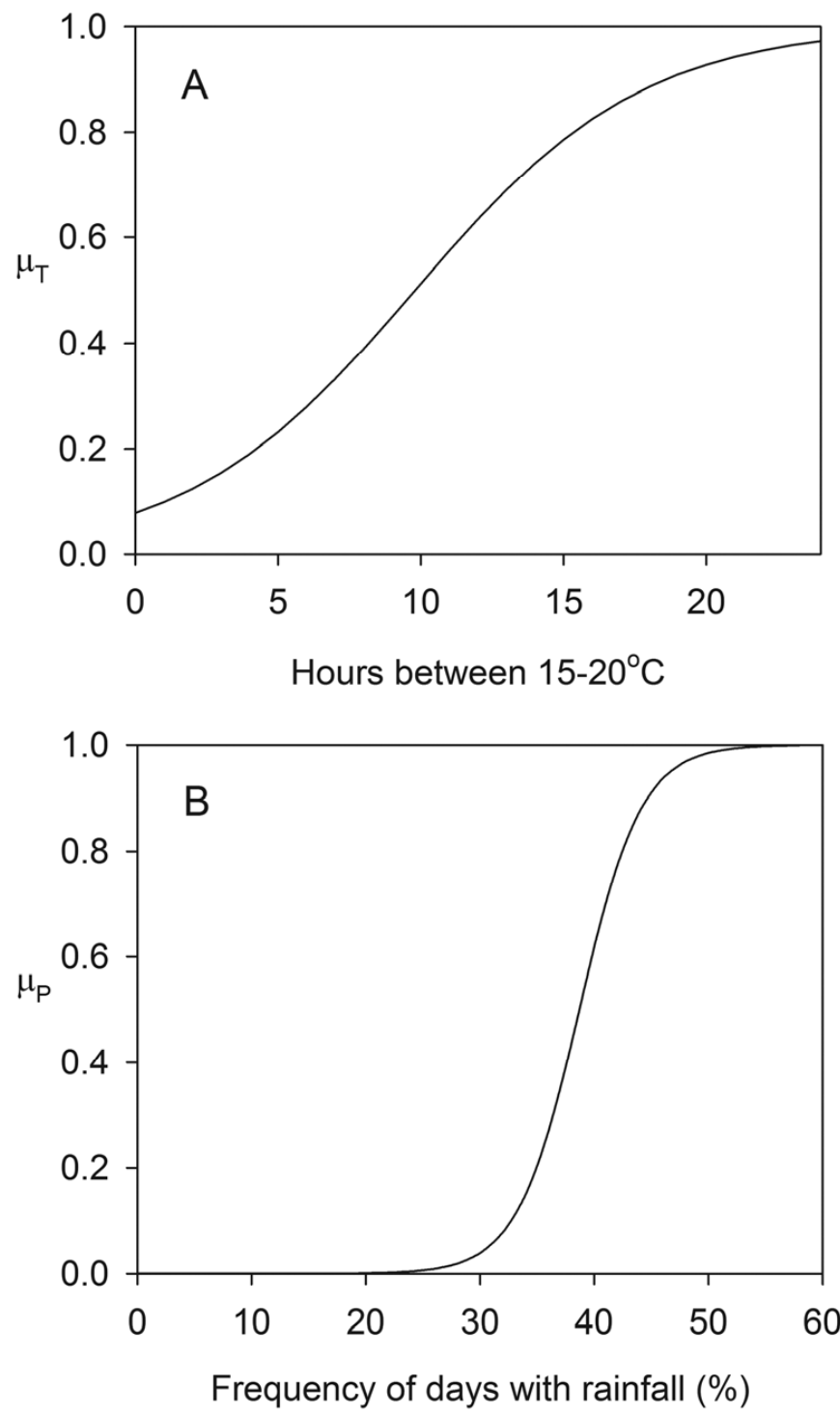

Fig. 1. Membership functions of temperature and rainfall frequency variables to assess the risk of boysenberry downy mildew in a month: $\mathbf{A}$, daily average hours between 15 to $20^{\circ} \mathrm{C}, \mu_{T}$, and $\mathbf{B}$, frequency of days with rainfall $(\%), \mu_{P}$. analysis, were used as the values of the $K$ parameters for $\mu_{T}$ and $\mu_{P}$, respectively. Search spaces for the $S$ parameters of $\mu_{T}$ and $\mu_{P}$ were defined using visual inspection. Once sets that represented the search space for each parameter were defined, every member of the set was used to determine the $S$ parameters that resulted in the highest degree of agreement statistics between binary risks (e.g., high or low) classified from $R_{H}$ values and disease observations. JMP (version 9.0; SAS institute Inc.) was used to perform degree of agreement analysis. Disease observations in Nelson in 2000 to 2009 were used as a calibration set to determine the parameters.

Daily risk simulation of $\boldsymbol{P}$. sparsa. The FPS model was used to simulate daily risk assessment of $P$. sparsa using a moving window of 30 days. The average number of hours in a specified temperature range for 24-h periods and the frequency of days with rain in the moving window were calculated and used as input to the FPS model. As an initial condition for the risk simulation using the FPS model, the value of $\Phi_{r}$ was determined from temperature and rainfall data collected for 30 days in the reference month. For example, weather data of 2 to 31 December in a season were used to calculate $\Phi_{r}$ at the Wasco site. Then, the starting date of the window was incremented by 1 day and $\Phi_{m}$ was calculated. The last day in the moving window was indicated by $d$.

The daily risk $\left(R_{d}\right)$ of $P$. sparsa on a given day $d$ was determined using the values of $\Phi_{r}$ and $\Phi_{m}$ as inputs to equation 7 . When $R_{d}$ was $>0.5$, it was assumed that weather conditions were conducive to downy mildew on $d$. Daily risk simulation of downy mildew was performed at the Wasco site, for which a summary of daily disease observations has been reported (3). According to Aegerter et al. (3), each observation was made from 12 February to 27 April 1998 and 20 February to 15 May 1999, respectively. Thus, the daily risk simulation of the disease was performed on these days.

\section{RESULTS}

Identification of temperature and rainfall thresholds. Using the CART analysis, weather patterns associated with high risk of boysenberry downy mildew were identified.

The decision tree generated from the CART analysis indicated that months during which temperature and rainfall variables exceeded $9.8 \mathrm{~h}$ and $38.7 \%$, respectively, occurred in high-risk seasons with $>10 \%$ dryberry incidence observed at harvest (Fig. 2).

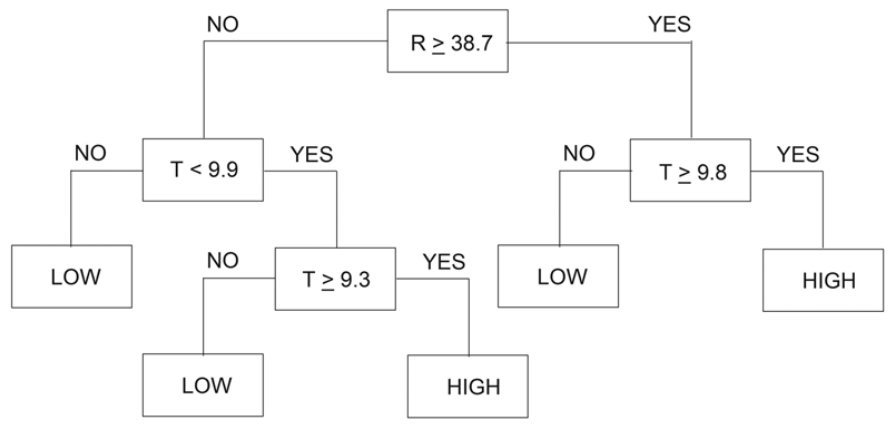

Fig. 2. The decision tree for identification of weather conditions associated with high risk of boysenberry downy mildew using a classification and regression tree (CART) analysis. The labels HIGH and LOW in the tree represent the seasonal risk of boysenberry downy mildew derived from disease incidence records at the end of season. The tree is interpreted such that a month with both $\mathrm{R} \geq 38.7 \%$ and $\mathrm{T} \geq 9.8 \mathrm{~h}$ is classified as a month in a HIGH risk season. $\mathrm{T}$ and $\mathrm{R}$ indicate the average number of hours per day between 15 and $20^{\circ} \mathrm{C}$ and the frequency $(\%)$ of days with rainfall in a month. The tree explained about $32 \%$ of variation in disease risk in the calibration data set. From the tree, thresholds of $\mathrm{T}$ and $\mathrm{R}$ were identified as $9.8 \mathrm{~h}$ and $38.7 \%$, respectively. 
For months in which the number of days with rain was $<38.7 \%$, a relatively complex decision tree was formed. However, this group of days with low rainfall frequency was ignored because it represented low-risk months in a season with high incidence of infection. For temperature in the CART analysis, the average number of hours at 15 to $20^{\circ} \mathrm{C}$ was selected over the number of hours at 20 to $25^{\circ} \mathrm{C}$ for favorability for downy mildew development. As a result, the thresholds for temperature and rainfall were determined to be $9.8 \mathrm{~h}$ /day at 15 to $20^{\circ} \mathrm{C}$ and $38.7 \%$ in a given month, respectively.

Classification of a season using only the thresholds of temperature and rainfall (i.e., $>9.8 \mathrm{~h} /$ day and $>38.7 \%$ ) agreed with
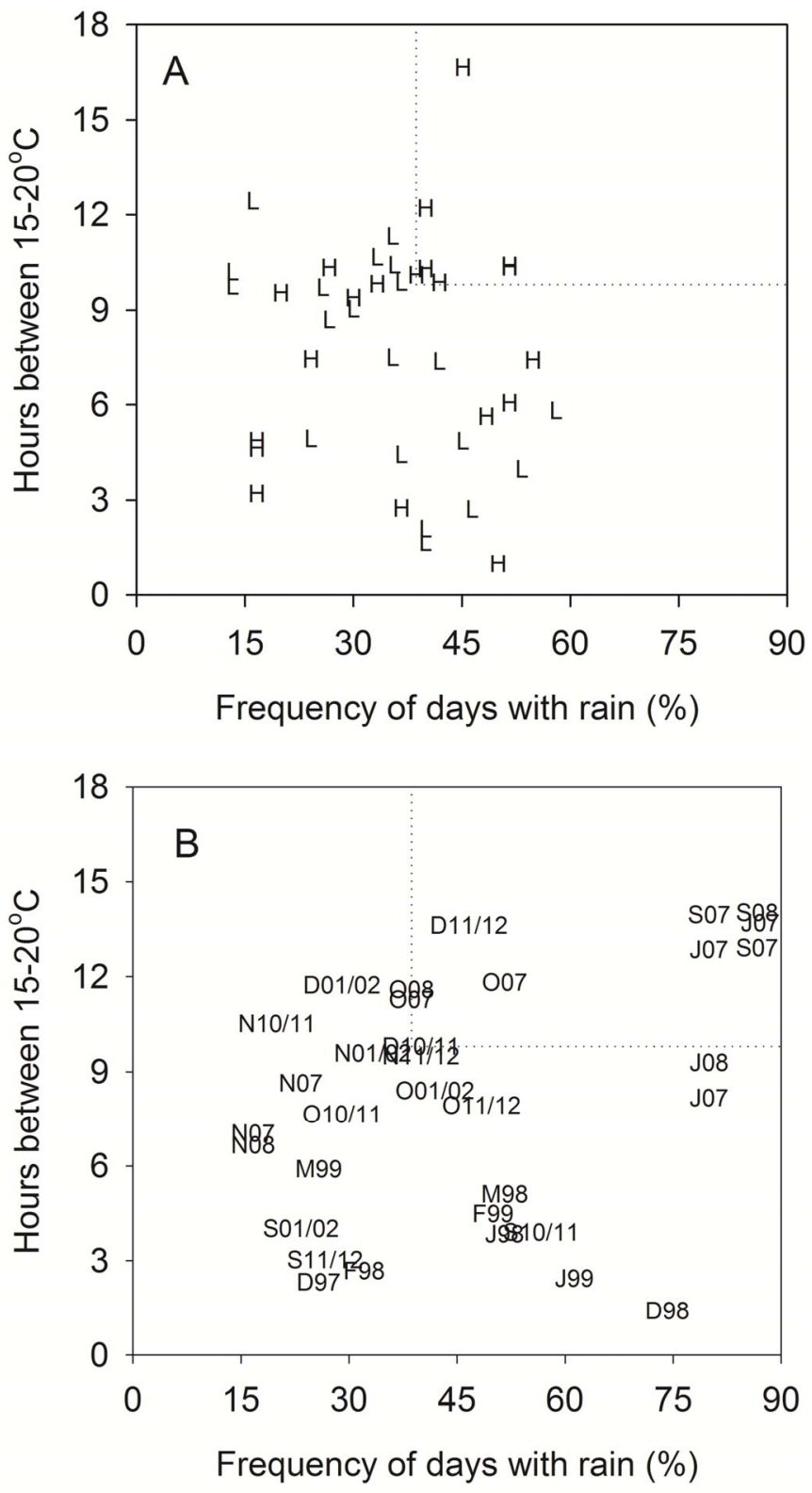

Fig. 3. Monthly weather conditions for $\mathbf{A}$, calibration sets in Nelson from October to December in 2000 to 2009. H and L denote high (incidence of $>10 \%$ ) and low risk in a given season, respectively, and $\mathbf{B}$, validation sets in Nelson (2010/11 and 2011/12), Hawke's Bay (2001), Wasco (1998 to 1999), Tangancicua (2007 to 2008), and Atapan (2007). The letters in B represent the first letter of a month. The number following that letter indicates the year during which monthly data were obtained. For example, D11/12 indicates December 2011 in 2011/2012 season. Although the same letter was used to represent a specific month, there is difference in seasonality between Wasco (winter through early spring), Tangancicua (early summer to autumn), Atapan (early summer to autumn), and Nelson and Hawke's Bay (spring through early summer), which are in the Northern and Southern hemispheres, respectively. disease observations in the calibration data (Fig. 3A). For example, the frequency of rain days $>38.7 \%$ occurred in December 2001, 2005, and 2006. At the same time, periods with 15 to $20^{\circ} \mathrm{C}$ $>9.8 \mathrm{~h}$ occurred during the same months. In these seasons, incidence of boysenberry downy mildew was $>10 \%$. When serious infection (e.g., incidence of $>70 \%$ ) occurred in 2005 and 2006, rainfall occurred on $\approx 52 \%$ of days in December 2005 and October 2006. Thus, frequent rainfall (i.e., $>38.7 \%$ of rain day in a month) represented favorable conditions for development of downy mildew in the study area. In contrast, when the threshold for the temperature variable was not met, fruit disease incidence was relatively small (e.g., $<10 \%$ of incidence), even with $>50 \%$ of rain days during a season. For example, incidence of downy mildew in 2007 was $\approx 2 \%$, although the rainfall occurred for $>50 \%$ of days in October in 2007.

Parameters of the model based on fuzzy sets. The thresholds obtained from the CART analysis (i.e., $9.8 \mathrm{~h}$ and $38.7 \%$ for $\mu_{T}$ and $\mu_{P}$, respectively) were used as values for $K$ parameters. The $S$ parameters of $\mu_{T}$ and $\mu_{P}$ for the FPS model were 0.25 and 0.37 , respectively (Fig. 2). The FPS model using those parameters had $100 \%$ accuracy in calibration.

Validation of the model based on thresholds and fuzzy sets. The thresholds identified from the CART analysis were not useful to predict the risk of downy mildew (Fig. 3B; Table 2). For example, there was no month in which the temperature was 15 to $20^{\circ} \mathrm{C}$ for $>9.8 \mathrm{~h}$ /day in 1998 in Wasco, whereas Aegerter et al. (3) reported a serious outbreak of rose downy mildew in that season. Degree of agreement analysis also indicated that predicted and observed risks of downy mildew using the thresholds were different $(P=0.051)$. Hence, these results favored application of fuzzy sets for development of the risk prediction model for the disease.

The FPS models identified the seasons in which the incidence was not estimated correctly by using both temperature and rainfall thresholds identified from the CART analysis (Table 2). For example, the FPS model estimated low risk of boysenberry downy mildew in 2011, when virtually no disease symptoms were found in the orchards. In contrast, both temperature and rainfall thresholds from the CART analysis indicated high incidence of the disease in the same season (Fig. 3B). The degree of agreement analysis indicated that the risk predicted from the FPS model was identical to the risks observed from validation sites in New Zealand, Mexico, and the United States $(P=0.002)$.

Daily risk simulation of $\boldsymbol{P}$. sparsa. When a moving windows approach was applied to the FPS model, the model had accurate prediction of downy mildew risk. According to Aegerter et al. (3), weather conditions were conducive to downy mildew for 61 of 63 days during which daily disease observations were obtained in the

TABLE 2. Comparison between observed and predicted risk of boysenberry, rose, and blackberry downy mildew using the Fuzzy Peronospora Sparsa (FPS) model

\begin{tabular}{lllll}
\hline & & \multicolumn{3}{c}{ Risk $^{\mathrm{a}}$} \\
\cline { 3 - 5 } Locality & Season & Obs $^{\mathrm{b}}$ & FPS $\left(R_{H}\right)^{\mathrm{c}}$ & TH $^{\mathrm{d}}$ \\
\hline Nelson & $2010-11$ & Low & Low $(0.24)$ & Low \\
Nelson & $2011-12$ & High & High $(0.99)$ & High \\
Hawke's Bay & $2001-02$ & High & High $(0.99)$ & Low \\
Wasco & 1998 & High & High (0.99) & Low \\
Wasco & 1999 & Low & Low $(0.31)$ & Low \\
Tangancicuaro & 2007 & High & High $(0.58)$ & High \\
Tangancicuaro & 2008 & High & High $(0.51)$ & High \\
Atapan & 2008 & High & High $(0.50)$ & High \\
\hline
\end{tabular}

a Incidence of $>10 \%$ represents the high risk of downy mildew disease in a season.

${ }^{\mathrm{b}}$ Incidence assessed in the study area.

${ }^{\mathrm{c}}$ FPS and $R_{H}$ represent the FPS model and the outcomes of risk prediction function (eq. 8, see text) in a given season.

$\mathrm{d}$ Thresholds derived from the classification and regression tree analysis. 
1998 season at Wasco site. At the same site, the FPS model predicted high risk of downy mildew from 12 February to 14 April, except for 4 days from 23 February in the 1998 season (Fig. 4). The model proposed by Aegerter et al. (3) identified weather conditions conducive to downy mildew correctly for 47 days in the 1998 season (Table 3). On the other hand, high risk of downy mildew (e.g., $R_{H}>0.5$ ) was predicted correctly for 46 days at the worst case using the FPS model in the same season (Table 3; Fig. 4). In the 1999 season, during which no lesions were found (3), there was no day when high risk of downy mildew was predicted using the FPS model (Table 3). However, Aegerter's model classified 15 days as conducive in the 1999 season. In total, Aegerter's model had an accuracy of $79.1 \%$ whereas the FPS model had an accuracy of $88.5 \%$ at Wasco in the 1998 and 1999 seasons.

\section{DISCUSSION}

This study has demonstrated that seasons favorable to outbreaks of boysenberry downy mildew have distinctive weather patterns, and the model based on fuzzy sets was able to identify such seasons when a high incidence of the disease was likely to occur. Aegerter et al. (3) developed a regression model to predict the risk of disease caused by $P$. sparsa, which focused on detection of new infection. In contrast, the FPS model was designed to predict the risk of disease development at monthly intervals. Thus, direct comparison between the two models is not particularly appropriate. However, application of fuzzy sets allowed reasonable prediction of disease development, using the same knowledge and data on weather conditions for development of $P$. sparsa. In the FPS model, the rule that can be stated as "temperature condition is favorable and rainfall condition is favorable," has been evaluated to quantify the monthly risk of disease

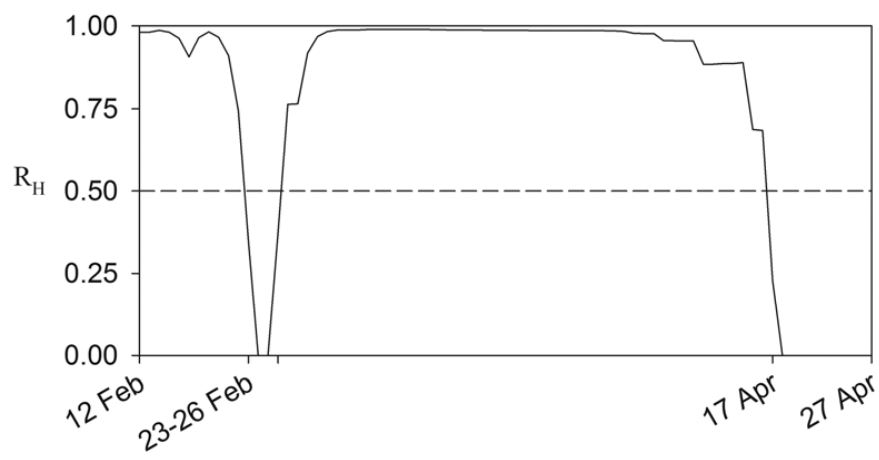

Fig. 4. Daily risk simulation of downy mildew in Wasco area using the Fuzzy Peronospora Sparsa (FPS) model from 12 February to 27 April 1998 during which Aegerter et al. (3) conducted daily disease assessment. During the time period indicated by the $x$ axis label, the FPS model predicted low risk of downy mildew, i.e., $R_{H}<0.5$, which corresponded with incidence of downy mildew. The dashed line represents 0.5 of $R_{H}$. development using equation 6. Equation 7 makes it easy to compare weather conditions between early periods and later periods within a growing season (e.g., between early spring and late spring). These features allow the FPS model to identify the relative suitability for disease development of months within a given site and season using the thresholds of weather variables suitable for downy mildew development.

Although the FPS model was developed and tested in relation to monthly risk of $P$. sparsa, a moving window approach allowed the FPS model to predict daily downy mildew risk. For example, the FPS model provided more accurate prediction of daily risk $(88.5 \%)$ than the model proposed by Aegerter et al. (3) $(79.1 \%)$ at Wasco during both the 1998 and 1999 seasons. It was not possible to compare daily risk accuracy between the FPS model and Aegerter's model on a day-by-day basis due to lack of detailed disease observation data. Thus, accuracy of the FPS model was set to the minimum, assuming that all of the nonconducive days classified from the FPS model were incorrect in the 1998 season. Nevertheless, the accuracy of the FPS model was greater than that of Aegerter's model. This suggests that the FPS model would be useful for a disease warning system at submonthly time resolution (e.g., weekly). Furthermore, the FPS model correctly identified nonconducive days when no disease occurred in a season, which could make it possible to reduce the number of fungicide spray applications considerably.

The FPS model provided reasonable prediction of downy mildew outbreaks for boysenberry, rose, and blackberry under different geographic and environmental conditions (e.g., Mexico, California in the United States, and the South and North Islands in New Zealand). Thus, it would be worthwhile to validate the FPS model in a wide range of areas where both local weather data and disease observations were available. For example, Achar (1) reported that rose downy mildew occurred in KwaZulu Natal, South Africa in 1996. There was a GSOD weather station near KwaZulu Natal. However, no weather data were available during that season. Furthermore, it was not possible to use the POWER data sets because rainfall data were missing. Thus, the FPS model was not tested in KwaZulu Natal area. Because of the sporadic nature of $P$. sparsa outbreaks in boysenberry, blackberry, and rose, an international collaboration would facilitate further validation study for the FPS model for downy mildew prediction in these crops.

Leaf wetness duration and temperature conditions can represent the actual environmental conditions associated with infection by $P$. sparsa (3). However, leaf wetness duration is rarely available from conventional weather data services and, if available, management of hourly data is required. This would make it difficult to operate a disease warning system for $P$. sparsa outbreaks in many regions. As shown in this study, outbreaks of boysenberry downy mildew can be predicted reasonably using the FPS model, using monthly summaries of daily rainfall occurrence and hours at 15 to $20^{\circ} \mathrm{C}$. Therefore, the FPS model would facilitate implementation

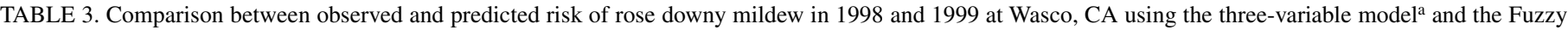
Peronospora Sparsa (FPS) model

\begin{tabular}{|c|c|c|c|c|c|c|c|c|c|}
\hline \multirow[b]{2}{*}{ Year } & \multirow[b]{2}{*}{ Total days } & \multicolumn{4}{|c|}{ Three-variable model (days) ${ }^{b}$} & \multicolumn{4}{|c|}{ FPS model (days) ${ }^{\mathrm{b}}$} \\
\hline & & $\mathrm{T} / \mathrm{T}^{\mathrm{c}}$ & $\mathrm{T} / \mathrm{F}^{\mathrm{c}}$ & $\mathrm{F} / \mathrm{T}^{\mathrm{c}}$ & $\mathrm{F} / \mathrm{F}^{\mathrm{c}}$ & $\mathrm{T} / \mathrm{T}^{\mathrm{c}}$ & $\mathrm{T} / \mathrm{F}^{\mathrm{c}}$ & $\mathrm{F} / \mathrm{T}^{\mathrm{c}}$ & $\mathrm{F} / \mathrm{F}^{\mathrm{C}}$ \\
\hline 1998 & 63 & 47 & 14 & 0 & 2 & 46 & 15 & 2 & 0 \\
\hline 1999 & 85 & 0 & 0 & 17 & 68 & 0 & 0 & 0 & 85 \\
\hline All & 148 & 47 & 14 & 17 & 70 & 46 & 15 & 2 & 85 \\
\hline
\end{tabular}

a Three-variable model described by Aegerter et al. (3).

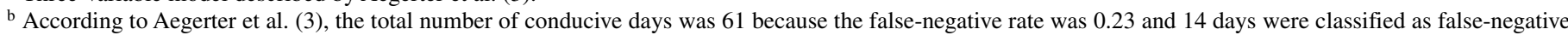
days. Furthermore, these conducive days occurred only in 1998. On the other hand, the total number of days for correct nonconducive classification and falsepositive classification were 70 and 17, respectively. Because no infection was observed in 1999, there were 2 days when no infection was observed in 1998. It was assumed that all 15 nonconducive days and 2 conducive days classified by the FPS model were incorrect for 63 days from a period from 12 February to 27 April in 1998.

c T/T, T/F, F/T, and F/F represent the number of correct conducive, false negative, false positive, and correct nonconducive days, respectively. 
of a disease warning system for boysenberry downy mildew at sites where no leaf wetness weather data are available.

The CART analysis was useful to determine parameters of the FPS model, although the CART analysis itself was not reliable in predicting the risk of boysenberry downy mildew. Because of the small number of calibration sets, the CART analysis was performed for individual months rather than for combinations of months, and this may have contributed to its poor prediction for boysenberry downy mildew risk. The FPS model, on the other hand, was able to use parameters derived from the CART analysis and was able to minimize the risk of local optimization, which causes greater accuracy in calibration yet larger error in validation. CART analysis was particularly valuable when used this way to identify thresholds of weather variables for subsequent use in a disease risk prediction model.

Aegerter et al. (3) indicated that a prolonged wetness duration may prevent the development of the disease. The FPS model depends on the assumption that wet and warm conditions early in the season (e.g., frequent rainfall and longer hours at 15 to $20^{\circ} \mathrm{C}$ ) would inhibit the possibility of high incidence of boysenberry downy mildew at the end of the season. However, it is unclear whether such an assumption would be valid in real orchards. The water potential of host plants early in a season could be associated with such findings. When frequent rainfall occurs early in a season, the water potential of the plants would be higher than that of plants in a dry, early season. Thus, small numbers of $P$. sparsa spores could be transported to the vascular tissue of a host in a season with early frequent rainfall. Alternatively, frequent rainfall early in a season could wash the spores or mycelium out of the orchards. These hypotheses need to be examined in a field experiment, and merit further studies on the epidemiology of boysenberry downy mildew in relation to weather conditions early in the season.

In the present study, the FPS model, which captures empirical relationships between disease risk and weather, was shown to be accurate across multiple regions and seasons. This study has also shown that the FPS model, which was developed using relatively coarse time resolution monthly weather data, was also accurate when used with daily temperature and rainfall data. This indicates that the FPS model would likely be useful for daily $P$. sparsa risk assessment as part of a system for tactical timing of fungicides for disease management in boysenberry, blackberry, or rose. A controlled-environment-based model (e.g., Aegerter et al. [3]), requires an empirical calibration study to ensure that it correctly captures the dependence of disease on weather conditions when it is applied in the field. Providing that an empirical model such as the FPS model is robust across regions and seasons, it has the advantage of being much simpler to develop than one derived from controlled-environment infection data, such as the Aegerter et al. (3) P. sparsa model. Thus, it is worthwhile to consider an empirical approach based on fuzzy sets in developing models for disease warning systems.

\section{ACKNOWLEDGMENTS}

The work was funded by Ministry of Agriculture and Forestry Sustainable Farming Fund (SFF) Grant SFF 08/077 in conjunction with the New Zealand Boysenberry Council Ltd. Daily weather data were obtained from the NASA Langley Research Center POWER Project funded through the NASA Earth Science Directorate Applied Science Program. We thank all participating growers for their generous in-kind support; G. Langford, Berryworld, for guidance; and J. Smith, Horteye, for data collection.

\section{LITERATURE CITED}

1. Achar, P. N. 1997. First report of downy mildew disease of rose caused by Peronospora sparsa in KwaZulu Natal, Southern Africa. Plant Dis. 81:695-695.

2. Aegerter, B. J., Nuñez, J. J., and Davis, R. M. 2002. Detection and management of downy mildew in rose rootstock. Plant Dis. 86:1363-1368.

3. Aegerter, B. J., Nuñez, J. J., and Davis, R. M. 2003. Environmental factors affecting rose downy mildew and development of a forecasting model for a nursery production system. Plant Dis. 87:732-738.

4. Beresford, R. M., and Kim, K. S. 2011. Identification of regional climatic conditions favorable for development of European canker of apple. Phytopathology 101:135-146.

5. Breese, W. A., Shattock, R. C., Williamson, B., and Hackett, C. 1994. In vitro spore germination and infection of cultivars of Rubus and Rosa by downy mildews from both hosts. Ann. Appl. Biol. 125:73-85.

6. Breiman, L., Friedman, J., Stone, C. J., and Olshen, R. A. 1984. Classification and Regression Trees. Chapman \& Hall, Boca Raton, FL.

7. Duthie J. A. 1997. Models of the response of foliar parasites to the combined effects of temperature and duration of wetness. Phytopathology 77:1088-1095.

8. Gleason, M. L., MacNab, A. A., Pitblado, R. E., Ricker, M. D., East, D. A., and Latin, R. X. 1995. Disease-warning systems for processing tomatoes in Eastern North America: Are we there yet? Plant Dis. 79:113121.

9. Hagan, A. K., Olive, J. W., Stephenson, J., and Rivas-Davila, M. E. 2000. Chemical control of downy mildew on rose. SNA Res. Conf. 45:214-217.

10. Hall, H. K., and Shaw, C. G. 1982. Oospores of Peronospora sparsa Berk. on Rubus species. N. Z. J. Exp. Agric. 10:429-432

11. Kari, J. S., and Huey, R. B. 2000. Size and seasonal temperature in freeranging Drosophila subobscura. J. Therm. Biol. 25:267-272.

12. Kim, K. S., and Beresford, R. M. 2012. Use of a climatic rule and fuzzy sets to model geographic distribution of climatic risk for European canker (Neonectria galligena) of apple. Phytopathology 102:147-157.

13. Klir, G. J., and Yuan, B. 1995. Fuzzy Sets and Fuzzy Logic: Theory and Applications. Prentice Hall PTR, Upper Saddle River, NJ.

14. O'Neill, T. M., Pye, D., and Locke, T. 2002. The effect of fungicides, irrigation and plant density on the development of Peronospora sparsa, the cause of downy mildew in rose and blackberry. Ann. Appl. Biol. 140:207-214.

15. Rebollar-Alviter, A., Silva-Rojas, H. V., Lopez-Cruz, I., Boyzo-Marin, J., and Ellis, M. A. 2012. Fungicide spray programs to manage downy mildew (dryberry) of blackberry caused by Peronospora sparsa. Crop Prot. 42:49-55.

16. Reicosky, D. C., Winkelman, L. J., Baker, J. M., and Baker, D. G. 1989. Accuracy of hourly air temperatures calculated from daily minima and maxima. Agric. For. Meteorol. 46:193-209.

17. Tate, K. G. 1981. Aetiology of dryberry disease of boysenberry in New Zealand. N. Z. J. Exp. Agric. 9:371-376.

18. Tate, K. G. 1983. Control of dryberry disease (Peronospora sparsa) in boysenberry with fungicides. N.Z. J. Exp. Agric. 11:141-146.

19. Thompson, S., Levin, S., and Rodriguez-Iturbe, I. 2013. Linking plant disease risk and precipitation drivers: A dynamical systems framework. Am. Nat. 181:E1-E16.

20. Walter, M., Harris-Virgin, P., Thomas, W., Tate, K. G., Waipara, N. W., and Langford, G. I. 2004. Agrochemicals suitable for downy mildew control in New Zealand boysenberry production. Crop Prot. 23:327-333.

21. Xu, X. M., and Pettitt, T. 2004. Overwintering of rose downy mildew (Peronospora sparsa). Pages 99-106 in: Advances in Downy Mildew Research. P. Spencer-Phillips and M. Jeger, eds. Kluwer Academic Publishers, Dordrecht, The Netherlands. 